Provided for non-commercial research and education use. Not for reproduction, distribution or commercial use.

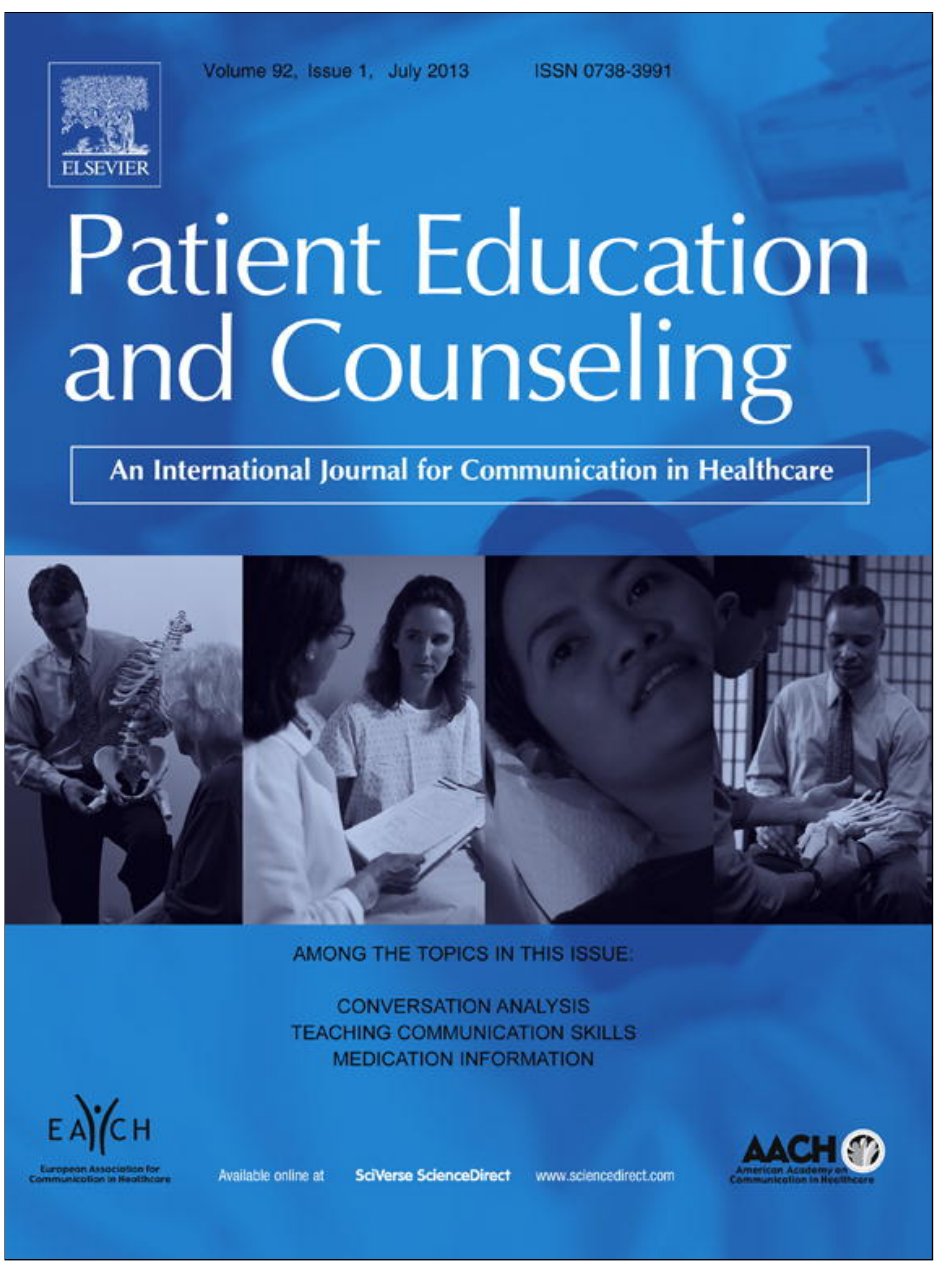

This article appeared in a journal published by Elsevier. The attached copy is furnished to the author for internal non-commercial research and education use, including for instruction at the authors institution and sharing with colleagues.

Other uses, including reproduction and distribution, or selling or licensing copies, or posting to personal, institutional or third party websites are prohibited.

In most cases authors are permitted to post their version of the article (e.g. in Word or Tex form) to their personal website or institutional repository. Authors requiring further information regarding Elsevier's archiving and manuscript policies are encouraged to visit:

http://www.elsevier.com/authorsrights 
Self Management

\title{
Comparison of self-care behaviors of heart failure patients in 15 countries worldwide
}

\author{
Tiny Jaarsma ${ }^{\mathrm{a}, *}$, Anna Strömberg ${ }^{\mathrm{b}, \mathrm{c}}$, Tuvia Ben Gal ${ }^{\mathrm{d}}$, Jan Cameron ${ }^{\mathrm{e}}$, Andrea Driscoll ${ }^{\mathrm{f}}$ \\ ${ }^{a}$ Department of Social and Welfare Studies, Linköping University, Linköping, Sweden \\ ${ }^{\mathrm{b}}$ Department of Medicine and Health Sciences, Linköping University, Linköping, Sweden \\ ${ }^{\mathrm{c}}$ Department of Cardiology, County Council of Östergötland, Linköping, Sweden \\ ${ }^{\mathrm{d}}$ Heart Failure Unit, Rabin Medical Center, Petah Tikva, Affiliated to the Sackler Faculty of Medicine, Tel Aviv University, Israel \\ ${ }^{\mathrm{e}}$ Cardiovascular Research Centre, Australian Catholic University, Melbourne, Australia \\ ${ }^{\mathrm{f}}$ School of Nursing and Midwifery, Deakin University, Melbourne, Australia \\ ${ }^{\mathrm{g}}$ Department of Cardiology, Charité University Hospital, Berlin, Germany \\ ${ }^{\mathrm{h}}$ Department of Cardiovascular Medicine, The University of Tokyo Graduate School of Medicine, Tokyo, Japan \\ ${ }^{i}$ Department of Cardiology \& Angiology I, University Heart Center Freiburg-Bad Krozingen, Freiburg, Germany \\ ${ }^{\mathrm{j}}$ Department of Nursing Science, Charité - Universitätsmedizin Berlin, Germany \\ ${ }^{\mathrm{k}}$ Unitat d'Insuficiència Cardíaca, Hospital Universitari Germans Trias i Pujol, Badalona, Spain \\ ${ }^{1}$ College of Nursing, University of Kentucky, Lexington, KY, USA \\ ${ }^{\mathrm{m}}$ Clinical Nursing Department, Thai Nguyen University of Medicine and Pharmacy, Thailand \\ ${ }^{\mathrm{n}}$ Heart Failure Unit/Cardiology Unit/CCU, S.Camillo-Forlanini Hospital, Rome, Italy \\ ${ }^{\circ}$ Cardiology Division, School of Nursing at Federal University of Rio Grande do Sul, Hospital de Clinicas de Porto Alegre, Brazil \\ ${ }^{\mathrm{p}}$ Walailak University, School of Nursing, Tasala, Nakhon Si Thammarat, Thailand \\ ${ }^{\mathrm{q}}$ Department of Nursing, Chang Gung University of Science and Technology, Taiwan \\ ${ }^{\mathrm{r}}$ School of Nursing, Tor Vergata University, Rome, Italy \\ ${ }^{\mathrm{s}}$ The Chinese University of Hong Kong, Hong Kong \\ ${ }^{\mathrm{t}}$ University of Pennsylvania School of Nursing , Philadelphia, USA
} Hans-Dirk Duengen $^{\mathrm{g}}$, Simone Inkrot ${ }^{\mathrm{g}}$, Tsuey-Yuan Huang ${ }^{\mathrm{q}}$, Nguyen Ngoc Huyen ${ }^{\mathrm{m}}$, Naoko Kato ${ }^{\mathrm{h}}$, Stefan Köberich ${ }^{\mathrm{i}, \mathrm{j}}$, Josep Lupón ${ }^{\mathrm{k}}$, Debra K. Moser ${ }^{1}$, Giovanni Pulignano ${ }^{\mathrm{n}}$, Eneida Rejane Rabelo ${ }^{\mathrm{o}}$, Jom Suwanno $^{\mathrm{p}}$, David R. Thompson ${ }^{\mathrm{e}}$, Ercole Vellone ${ }^{\mathrm{r}}$, Rosaria Alvaro ${ }^{\mathrm{r}}$, Doris $\mathrm{Yu}^{\mathrm{s}}$, Barbara Riegel ${ }^{\mathrm{t}}$

A R T I C L E I N F O

\section{Article history:}

Received 14 September 2012

Received in revised form 9 January 2013

Accepted 24 February 2013

\section{Keywords:}

Self-care

International

Disease management

Heart failure

Cardiac

\begin{abstract}
A B S T R A C T
Objective: Clinicians worldwide seek to educate and support heart failure patients to engage in self-care. We aimed to describe self-care behaviors of patients from 15 countries across three continents. Methods: Data on self-care were pooled from 5964 heart failure patients from the United States, Europe, Australasia and South America. Data on self-care were collected with the Self-care of Heart Failure Index or the European Heart Failure Self-care Behavior Scale.

Results: In all the samples, most patients reported taking their medications as prescribed but exercise and weight monitoring were low. In 14 of the 22 samples, more than $50 \%$ of the patients reported low exercise levels. In 16 samples, less than half of the patients weighed themselves regularly, with large differences among the countries. Self-care with regard to receiving an annual flu shot and following a low sodium diet varied most across the countries.

Conclusion: Self-care behaviors are sub-optimal in heart failure patients and need to be improved worldwide.

Practice implications: Interventions that focus on specific self-care behaviors may be more effective than general educational programs. Changes in some health care systems and national policies are needed to support patients with heart failure to increase their self-care behavior.
\end{abstract}

(c) 2013 Elsevier Ireland Ltd. All rights reserved

\footnotetext{
* Corresponding author at: Linköpings University, Department of Social- and Welfare Studies, ISV, 60174 Norrköping, Sweden. Tel.: +46 11363550. E-mail address: Tiny.jaarsma@liu.se (T. Jaarsma).
}

\section{Introduction}

Patients with heart failure (HF) who report more effective selfcare have lower mortality and readmission rates than those who report poor self-care [1]. Self-care is a process of maintaining health through health promoting practices, symptom monitoring 
and managing symptoms when they occur [2]. HF specific self-care includes activities aimed at self-care maintenance (e.g., taking medication, exercising), symptom monitoring (e.g., monitoring weight changes) and symptom management (e.g., calling a health care provider or taking extra diuretics with symptoms of fluid retention) [2-5]. Self-care is considered important in the comprehensive management of patients with $\mathrm{HF}$ and is the focus of HF management programs internationally. Advice on HF selfcare behaviors is often similar, regardless of the geographic location of the patient [6-8].

Worldwide, optimization of self-care is a focus of healthcare in order to improve survival and well-being as well as to prevent hospitalizations [6-9]. At the same time, there are substantial differences in health care systems, patient education approaches, and the role of nurses in HF care along with limited availability of HF management programs in some countries [10]. Country specific challenges likely exist due to lack of resources, for example, salt restricted or healthy foods may be difficult to purchase in some countries [11] and weighing scales may not be affordable. There also are cultural differences in reactions to symptoms, as described in response to symptoms of a myocardial infarction [12]. In some countries it might be difficult or unusual to access a health care provider for HF symptoms. Migration (both voluntary and forced) might also increase the complexity of self-care for individual patients [13].

In order to target and individualize specific needs of HF patients in each country, it is important to have a description of self-care practices in different countries. A first report comparing self-care in developed and developing countries found differences in selfcare across counties and demonstrated that self-care was not adequate in the majority of samples studied [14]. That study focused mainly on the concepts of self-care maintenance, self-care management and self-care confidence and less on specific self-care behaviors. We know little about how comparable specific self-care behaviors are across countries, cultures and populations and therefore aimed to compare five recommended heart failure specific self-care behaviors in countries across the world.

\section{Methods}

This study was a secondary analysis of data on HF self-care pooled from 22 samples of HF patients across three different parts of the United States, six countries in Europe, seven in Australasia, and one in South America, totaling 5964 HF patients. The actual data were obtained from the original researchers and sent in an SPSS or excel file to the first author. A research assistant assisted with integration of the individual data files into a single file for analysis. After analysis in SPSS, the original researchers checked for appropriate reporting and interpretation of the data.

If study participants were enrolled into an intervention involving education about $\mathrm{HF}$, data were included only if patients had not received a structured, planned educational intervention prior to data collection. Data had been collected with the Self-care of Heart Failure Index (SCHFI) or the European Heart Failure Selfcare Behavior Scale (EHFScB). These scales address many of the same behaviors (e.g., exercise, weighing, medication taking).

SCHFI: Both the SCHFI v.4 and SCHFI v. 6 were used in data collection, but the items used were essentially the same in both versions. The SCHFI v.4 is a self-report questionnaire comprised of 15 items rated on a four-point response scale and divided into three scales measuring self-care maintenance, self-care management, and self-care confidence. Scores on each scale are standardized to range from 0 to 100 with higher scores indicating better self-care. In the original testing of this instrument, construct validity was demonstrated. Reliability, tested by Cronbach's alpha was $.56, .70$ and .82 for the self-care maintenance, self-care management and self-care confidence scales respectively. The SCHFI has been translated into numerous languages and is used worldwide to study the self-care of HF patients. The SCHFI was updated in 2009 with the addition of 7 items, including questions about medication adherence $[15,16]$.

$E H F S c B$ : The European Heart Failure Self-Care Behavior Scale (EHFScB scale) was developed to measure the behaviors that HF patients perform to maintain life, healthy functioning, and wellbeing [17]. The EHFScB has 12 items rated on a 5-point scale between 1 (I completely agree) and 5 (I completely disagree). Higher scores indicate worse self-care. Items address HF self-care maintenance (e.g., regular weighing, diet, fluids), self-care monitoring, and self-care management (e.g., warn a health care provider in case of weight gain). After initial testing of the 12 item version, a 9-item version was developed by deleting 3 items [18]. Data from both the 9-item and 12-item scale are included in the current analysis since the individual items were unchanged. Validity and reliability of both the 9-item version and the 12-item version have been tested in at least 10 other populations with different linguistic characteristics [19-23].

In this study, the scores of separate items of SCHFI and EHFScB scale were used at the item level, as shown in Table 1. In addition to data on self-care, researchers were also asked to provide basic demographic (age, gender, marital status) and clinical data (HF etiology, time since diagnosis, New York Heart Association [NYHA] functional class) and the proportion of the sample with HF of an ischemic etiology (atherosclerosis of the coronary arteries) collected in their samples. Since ischemic heart disease is the most common cause of HF we note it in Table 2.

\subsection{Data analysis}

Descriptive statistics were used to analyze the data on 5 selfcare behaviors. The proportion of subjects reporting low self-care on each of the 5 items is reported. Low self-care was defined on the SCHFI as: never/rarely or only sometimes performing these behaviors. Low self-care on the EHFScB scale was defined as not agreeing with the statement (scores 3, 4 and 5). In 3 samples, data

Table 1

Self-care behavior items in the Heart Failure of Self-care Index and the European Heart Failure Self Care Behavior scale.

\begin{tabular}{lll}
\hline Self care activity & SCHFI item & EHFScB-item \\
\hline $\begin{array}{l}\text { Restrict salt intake } \\
\text { Physical activity }\end{array}$ & $\begin{array}{l}\text { How routinely do you eat a low salt diet (never/rarely-always/daily) } \\
\text { How routinely do you do some physical activity } \\
\text { (never/rarely-always/daily) }\end{array}$ & $\begin{array}{l}\text { I eat a low salt diet (completely agree-completely disagree) } \\
\text { I exercise regularly (completely agree-completely disagree) }\end{array}$ \\
$\begin{array}{l}\text { Regular weighing } \\
\text { Flu shot }\end{array}$ & $\begin{array}{l}\text { How routinely do you weigh yourself (never/rarely-always/daily) } \\
\text { How routinely do you try to avoid getting sick }\end{array}$ & $\begin{array}{l}\text { I weigh myself every day (completely agree-completely disagree) } \\
\text { (e.g., flu shot, avoid ill people)? } \\
\text { (never/rarely-always/daily) Or: having an influenza vaccination annually }\end{array}$ \\
Medication & $\begin{array}{l}\text { How often do you forget to take one of your medicines? } \\
\text { (never/rarely-always/daily) }\end{array}$ & $\begin{array}{l}\text { I take my medication as prescribed (completely agree-completely } \\
\text { disagree) }\end{array}$ \\
\hline
\end{tabular}

SCHFI, Self-care of Heart Failure Index; EHFScB, European Heart Failure Self Care Behavior scale. 
Table 2

Descriptive data per country.

\begin{tabular}{|c|c|c|c|c|c|c|c|c|c|}
\hline Sample & $N$ & Scale & $\begin{array}{l}\text { Site and } \\
\text { design }\end{array}$ & $\begin{array}{l}\text { Mean } \\
\text { age (yrs) }\end{array}$ & Female & Married $^{\mathrm{a}}$ & NYHA I/II/III/IV & $\begin{array}{l}\text { Median time } \\
\text { since diagnosis } \\
\text { months }\end{array}$ & $\begin{array}{l}\text { \% ischemic } \\
\text { etiology }\end{array}$ \\
\hline \multicolumn{10}{|l|}{ Europe } \\
\hline Spain & 963 & EHFScB12 & $\mathrm{HFC}^{\mathrm{b}}$ & $67 \pm 13$ & $28 \%$ & $69 \%$ & $6 / 66 / 27 / 1$ & 7 & $53 \%$ \\
\hline \multicolumn{10}{|l|}{ Italy } \\
\hline Italy 1 & 609 & EHFScB12 & OPC/other ${ }^{\mathrm{b}}$ & $73 \pm 12$ & $43 \%$ & $53 \%$ & $22 / 37 / 32 / 9$ & 41 & $46 \%$ \\
\hline Italy2 & 210 & EHFScB12 & $\mathrm{HFC} / \mathrm{PC}^{\mathrm{b}}$ & $76 \pm 6$ & $43 \%$ & $61 \%$ & $0 / 45 / 48 / 7$ & - & $57 \%$ \\
\hline Netherlands & 967 & EHFScB12 & $\operatorname{Hosp}^{\mathrm{c}}$ & $71 \pm 11$ & $38 \%$ & - & $0 / 5 / 51 / 44$ & - & $43 \%$ \\
\hline \multicolumn{10}{|l|}{ Sweden } \\
\hline Sweden 1 & 147 & EHFScB9 & $\mathrm{HFC}^{\mathrm{C}}$ & $71 \pm 11$ & $33 \%$ & $64 \%$ & $4 / 59 / 34 / 3$ & - & $29 \%$ \\
\hline Sweden2 & 100 & EHFScB9 & $\mathrm{H}^{\mathrm{c}}$ & $81 \pm 9$ & $38 \%$ & $52 \%$ & $0 / 12 / 80 / 8$ & - & $65 \%$ \\
\hline Sweden 3 & 155 & EHFScB12 & $\mathrm{HFC}^{\mathrm{c}}$ & $71 \pm 11$ & $24 \%$ & $100 \%$ & $5 / 27 / 53 / 15$ & - & $40 \%$ \\
\hline \multicolumn{10}{|l|}{ Germany } \\
\hline Germany 1 & 135 & SCHFI & Hosp/HFC ${ }^{c}$ & $77 \pm 6$ & $57 \%$ & $59 \%$ & $30 / 48 / 22 / 0$ & 48 & $25 \%$ \\
\hline Germany2 & 90 & EHFScB9 & Hosp/HFC ${ }^{b}$ & $63 \pm 12$ & $27 \%$ & $66 \%$ & $6 / 55 / 36 / 3$ & - & $48 \%$ \\
\hline Serbia & 106 & SCHFI & Other ${ }^{\mathrm{c}}$ & $76 \pm 5$ & $32 \%$ & - & $16 / 80 / 4 / 0$ & 72 & $55 \%$ \\
\hline \multicolumn{10}{|l|}{ North America } \\
\hline US North East & 280 & SCHFI & $\operatorname{Hosp}^{\mathrm{b}}$ & $62 \pm 12$ & $36 \%$ & $57 \%$ & $4 / 19 / 59 / 18$ & 50 & $69 \%$ \\
\hline US South East & 351 & SCHFI & $\mathrm{H}^{\mathrm{b}}$ & $60 \pm 12$ & $33 \%$ & $56 \%$ & $7 / 41 / 41 / 10$ & 60 & $52 \%$ \\
\hline US Mexican South West & 134 & SCHFI & Hosp $^{c}$ & $72 \pm 11$ & $54 \%$ & $60 \%$ & $0 / 19 / 46 / 35$ & - & $52 \%$ \\
\hline \multicolumn{10}{|l|}{ South America } \\
\hline Brazil & 106 & EHFScB12 & Hosp $^{b}$ & $62 \pm 13$ & $35 \%$ & $70 \%$ & $5 / 28 / 52 / 13$ & 60 & $36 \%$ \\
\hline \multicolumn{10}{|l|}{ Australia } \\
\hline \multicolumn{10}{|l|}{ Australia } \\
\hline Australia1 & 572 & SCHFI & Hosp $/ \mathrm{H}^{\mathrm{c}}$ & $70 \pm 13$ & $36 \%$ & $62 \%$ & $0 / 57 / 31 / 11$ & 24 & $59 \%$ \\
\hline Australia2 Hosp ${ }^{\mathrm{b}}$ & 143 & SCHFI & & $71 \pm 11$ & $27 \%$ & $53 \%$ & $0 / 50 / 43 / 7$ & - & $56 \%$ \\
\hline \multicolumn{10}{|l|}{ Asia } \\
\hline Japan & 127 & EHFScB12 & $\mathrm{OPC}^{\mathrm{b}}$ & $64 \pm 16$ & $31 \%$ & $72 \%$ & $25 / 55 / 20 / 0$ & 29 & $27 \%$ \\
\hline Israel & 42 & EHFScB12 & $\mathrm{HFC}^{\mathrm{b}}$ & $62 \pm 9$ & $21 \%$ & $88 \%$ & $0 / 24 / 69 / 7$ & - & $83 \%$ \\
\hline Vietnam & 126 & EHFScB9 & Hosp $^{b}$ & $70 \pm 8$ & $52 \%$ & $46 \%$ & - & - & - \\
\hline Hong Kong & 167 & SCHFI & $\mathrm{HFC}^{\mathrm{b}}$ & $72 \pm 21$ & $61 \%$ & $43 \%$ & $7 / 46 / 46 / 2$ & - & $25 \%$ \\
\hline Thailand & 400 & SCHFI & Hosp/HFC ${ }^{b}$ & $65 \pm 14$ & $48 \%$ & $76 \%$ & $8 / 30 / 33 / 29$ & 27 & $55 \%$ \\
\hline Taiwan & 34 & SCHFI & Hosp $^{\mathrm{b}}$ & $61 \pm 18$ & $41 \%$ & $59 \%$ & $6 / 68 / 24 / 3$ & 11 & $29 \%$ \\
\hline
\end{tabular}

EHFScB, European Heart Failure Self-care Behavior; SCHFI, Self-care of Heart Failure Index; NYHA, New York Heart Association; HFC, Heart Failure clinic; OPC, outpatient clinic; PC, Primary Care; Hosp, hospital; H, Home; other, Cardiovascular Day Hospital, research clinic.

a Married or cohabiting.

b Data collected as part of a descriptive study.

c Data collected as part of a Randomized Controlled Trial.

were collected with both the SCHFI and the EHFScB scale (Hong Kong, Brazil and Italy). Only data from one of the scales (the one with the most complete items) was used in analysis (EHFScB in Italy and Brazil; SCHFI in Hong Kong). In some samples no data were collected on self-care related to medication adherence as a result of using the 15 item version of the SCHFI and in some samples no data were collected on the item about obtaining a yearly flu shot due to use of the 9-item version of the EHFScB scale.

\section{Results}

\subsection{Demographics}

Data were collected from small and large samples ranging in size from 34 patients (Taiwan) to 967 (Netherlands). In 12 samples the EHFScB scale was used to collect data, in 10 the SCHFI. Data were collected in heart failure clinics, home setting, outpatient departments, hospitals and research clinics. Data were collected from descriptive (cross-sectional or longitudinal) studies and from randomized control trials (pharmacological or non-pharmacological interventions) (Table 2). The mean age of the samples ranged from 60 years in an American sample to 81 years in one of the Swedish studies. All studies included both male and female patients (Table 2). The mean age of the total population was 69 with $38 \%$ female patients. Data had been collected in patients from all NYHA classes, mostly in NYHA classes II-III.

\subsection{Self-care}

Table 3 and Fig. 1 describe the results of the scoring on the separate items. The data reflect the percentage of persons in each sample who have difficulty with each self-care item.

Medication: In all samples most of the patients reported that they took their medication as prescribed. The median reported percentage of patients in the samples reporting not taking their medication was $7 \%$, reflecting that in half of the 22 samples $7 \%$ or less of the patients reported not performing this self-care behavior. The highest number of patients who reported not taking their medication on a regular basis or as prescribed was the sample from Israel. On the EHFScB scale, $19 \%$ of this sample did not agree with the statement 'I take my medication as prescribed'. (Fig. 1A)

Exercise: Self-reported exercise levels were low in most of the samples. Low rates of exercise (never/rarely/only sometimes on SCHFI or score $>2$ on the EHFScB scale) ranged from $36 \%$ in one of the samples from Germany to $90 \%$ in one of the Italian samples and $89 \%$ in the sample from Brazil. In 16 of the 21 samples, more than $50 \%$ of the patients reported low exercise levels (median 54\%) (Fig. 1B).

Weight monitoring: Weight monitoring (daily or routinely, see Table 1) was irregular in most samples, with the lowest number of people not weighing themselves regularly reported in one of the Australian samples (24\% reported not weighing) and the highest percentages of not weighing in the samples in Hong Kong (95\% reported not weighing) and Brazil (89\%). In 16 samples, less than 
Table 3

Low self-care per country. Low self-care was defined on the Self-care of Heart Failure Index as: never/rarely or only sometimes performing these behaviors. Low self-care on the European Heart Failure Self-care Behavior Scale was defined as not agreeing with the statement (scores 3, 4 and 5).

\begin{tabular}{|c|c|c|c|c|c|c|}
\hline Sample & $N$ & $\begin{array}{l}\text { Exercise } \\
\text { Low \% }\end{array}$ & $\begin{array}{l}\text { Weight monitoring } \\
\text { Low \% }\end{array}$ & $\begin{array}{l}\text { Flu shot } \\
\text { Low \% }\end{array}$ & $\begin{array}{l}\text { Medication } \\
\text { Low \% }\end{array}$ & $\begin{array}{l}\text { Sodium restriction } \\
\text { Low } \%\end{array}$ \\
\hline \multicolumn{7}{|l|}{ Europe } \\
\hline Spain & 963 & 62 & 78 & 40 & 3 & 25 \\
\hline \multicolumn{7}{|l|}{ Italy } \\
\hline Italy 1 & 609 & 54 & 60 & 23 & 15 & 35 \\
\hline Italy2 & 210 & 90 & 68 & 35 & 8 & 26 \\
\hline Netherlands & 967 & 44 & 62 & 18 & 2 & 18 \\
\hline \multicolumn{7}{|l|}{ Sweden } \\
\hline Sweden 1 & 147 & 61 & 67 & - & 7 & 56 \\
\hline Sweden2 & 100 & 82 & 34 & - & 0 & 40 \\
\hline Sweden3 & 155 & 62 & 59 & 38 & 1 & 35 \\
\hline Germany1 & 135 & 40 & 54 & 35 & 6 & 49 \\
\hline Germany2 & 90 & 36 & 48 & - & 3 & 60 \\
\hline Serbia & 106 & 51 & 73 & 45 & 13 & 48 \\
\hline \multicolumn{7}{|l|}{ North America } \\
\hline US North East & 280 & 43 & 39 & 17 & 2 & 26 \\
\hline US South East & 351 & 66 & 61 & 30 & - & 44 \\
\hline US Mexican South West & 134 & 74 & 82 & 40 & 13 & 41 \\
\hline \multicolumn{7}{|l|}{ South America } \\
\hline Brazil & 106 & 89 & 89 & 53 & 9 & 36 \\
\hline \multicolumn{7}{|l|}{ Australia } \\
\hline Australia 1 & 572 & 47 & 24 & 16 & - & 23 \\
\hline Australia 2 & 143 & 51 & 54 & 26 & 10 & 37 \\
\hline \multicolumn{7}{|l|}{ Asia } \\
\hline Japan & 127 & 53 & 46 & 52 & 2 & 45 \\
\hline Israel & 42 & 57 & 71 & 57 & 19 & 60 \\
\hline Vietnam & 126 & 41 & 43 & - & 10 & 22 \\
\hline Hong Kong & 167 & 83 & 95 & 75 & - & 63 \\
\hline Thailand & 400 & 53 & 83 & 37 & - & 53 \\
\hline Taiwan & 34 & 68 & 74 & 53 & - & 91 \\
\hline
\end{tabular}

half (median 61\%) of the patients weighed themselves regularly, with large differences between the countries (Fig. 1C).

Flu shot: Receiving an annual flu shot varied widely among the countries; $16-75 \%$ of patients reported not getting an annual flu shot (median 38\%). Countries with the highest percentage of patients not receiving a flu shot were Hong Kong, Israel, Brazil, Taiwan and Japan (Fig. 1D).

Sodium restriction: Self-care with regard to a sodium restricted diet varied more across the countries than other self-care behaviors. Between $18 \%$ and $91 \%$ (median $40 \%$ ) of patients reported not adhering to a low salt diet. (Never/rarely/only sometimes on SCHFI or score $>2$ on the EHFScB scale.) Countries where the highest percentage of patients reported following a sodium restricted diet were the Netherlands (18\%), Vietnam (22\%) and Australia (23\%). Countries with the highest percentage of patients not restricting their sodium intake were Taiwan (91\%) and Hong Kong (63\%) (Fig. 1E).

\section{Discussion and conclusion}

\subsection{Discussion}

This international study of important HF self-care behaviors demonstrates that there is wide variability in HF self-care across countries, but that there is markedly poor adherence to most selfcare behaviors regardless of country. Self-care behavior regarding medication adherence and exercise was similar in most countries, but we found large variations in adherence to weight monitoring, salt restriction and receiving an annual flu shot.

Culture is important to consider with regard to performance of self-care behaviors among patients with HF and delivery of support to perform self-care. We define culture as a set of shared attitudes, values, goals, and practices that characterize an institution, organization, or group [24]. Although we realize that within a country several cultures might exist and even within cultures, subcultures might have different values, use of the word culture rather than country fits the goal of our descriptive study. Numerous researchers have studied self-care previously, but results have not been compared across nations, across culturally diverse populations and across health care systems. We undertook this large-scaled comparison of divergent samples with unique health care systems and cultures to provide insight in possible similarities and differences in HF self-care across the world. This study adds to previous comparisons between self-care in developed and developing countries [14] and provides a broad reflection on international self-care that may help us to identify factors related to self-care behaviors and explore possible interventions to improve specific self-care behaviors worldwide.

Several explanations can be given for the differences in HF selfcare across the different samples. Self-care occurs in a context, which in this case refers to locations and countries of the participants. The self-care described in this article represents the behaviors and beliefs characteristic of a wide variety of cultures or social and ethnic groups from around the world. Besides the services (e.g., access to education in HF clinics) available in each country, every group surveyed probably has distinct cultural norms and practices surrounding foods and traditions that influenced their self-care [25].

Across all samples, we found high self-care in medication taking. Although we realize this is self-reported adherence which might not completely reflect actual practice, it is interesting to see that it was similar in all the samples. The local investigators reflected that in most of their cultures people have a strong belief in the benefits of medicine and have a 'doctor knows best' 


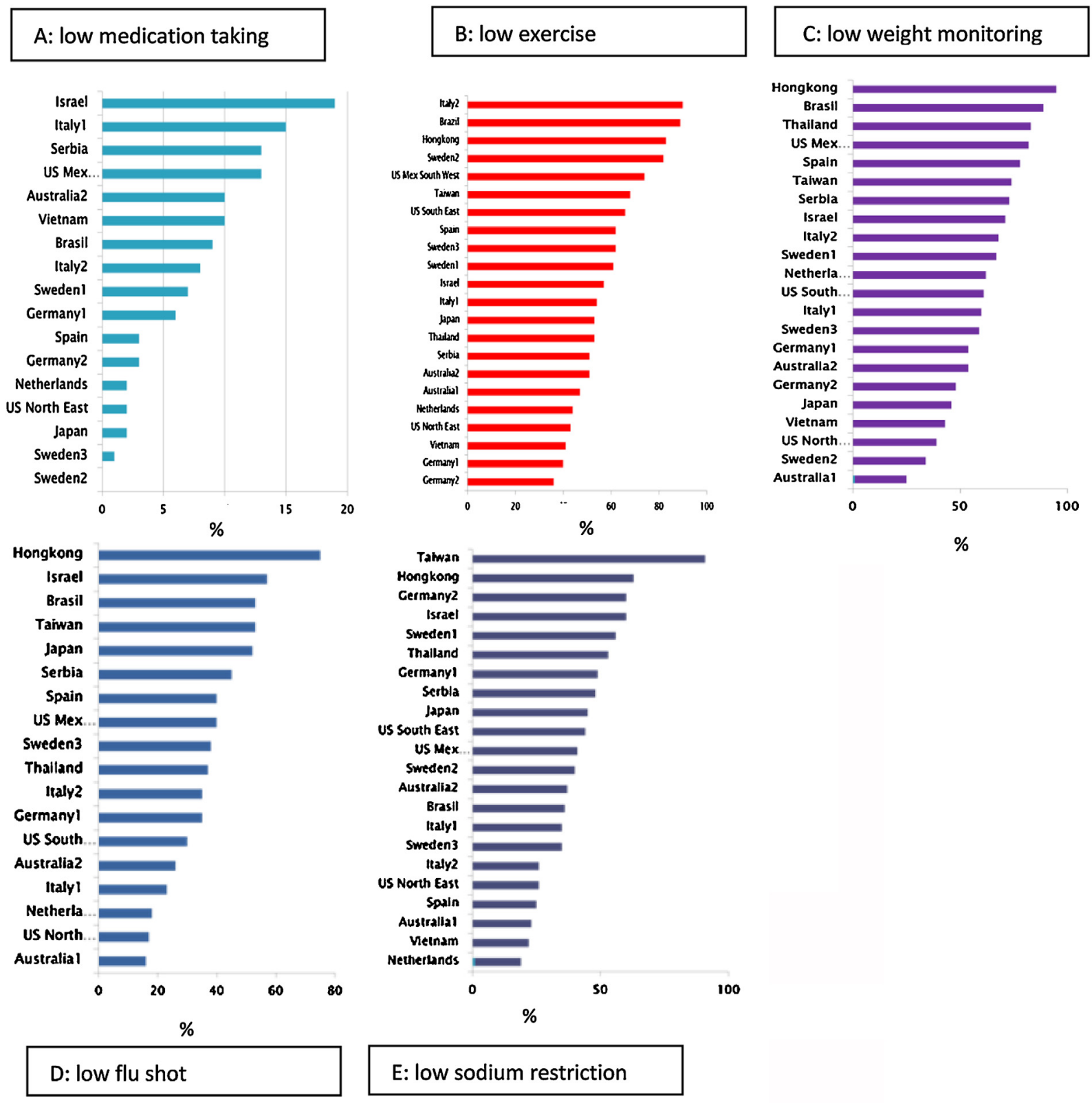

Fig. 1. Percentages of low self-care behaviors per country.

philosophy. Furthermore, medications (for the elderly) are subsidized in several countries and in some countries home care nurses support patients to organize their medication schedule. Although the reported data on self-care in medication taking are high, education and support to appropriately use medication is still needed. In many populations older adults often use nonprescription and inappropriate drugs or forget to take their medication [26-29]. Patients may use herbal medication or traditional medication in addition to prescribed pharmacotherapy and may not be aware of drug interactions [30]. In some countries patients use herbal medications/traditional medicine as a supplement or do not trust "western medication" since they feel it is made of chemical ingredients that come with many side effects [31,32].

In contrast to the high level of medication taking self-care behavior across samples, a consistently low level of exercise was found across the samples. In most samples more than half of the patients did not exercise regularly. This is in line with findings of the general older population in several countries. For example, in Brazil one third of individuals over 65 years of age do not engage in any kind of physical activity [33] and only 36\% of Australians aged 75 years and over walk for exercise [34]. In Italy, $31 \%$ of elderly men and $51 \%$ of elderly women do not engage in physical activity during their free time [35] and in Taiwan, only 44\% of elders engage in regular exercise [36]. At the same time it is known that older persons who exercise gain health benefits, so this self-care behavior is important for healthy elders. For HF patients, however, it is not always easy to begin exercising if this is not a typical behavior, due to symptoms [37]. In addition, the climate (e.g., cold weather in Sweden, rain in the Netherlands and heat in countries like Italy, Australia and Israel) can make it difficult for patients to leave their homes to engage in exercise. Within countries and continents differences can be seen due to cultural perceptions about exercise, climate, and available resources. For example, in the US samples, exercise was least common among the Hispanic patients enrolled in the southwestern US in spite of balmy weather, 
suggesting that cultural factors influenced behavior in this sample. Although some countries have rehabilitation programs or sport groups for cardiac patients, not all HF patients have access to these programs, and not all healthcare providers recommend this activity or tell patients how to do it [37].

Similar difficulties with regular weighing were observed in almost all of our samples. Realizing that these patients had not received any special education about their HF suggests that many may not have been aware of the importance of symptom monitoring. In several countries we included in the study, most people have a scale at home, although this seems to be more common in the younger and healthier population than in the sick and the elderly. At the same time, there might be countries in which purchasing a weighing scale is not on the priority list of family expenses and people sometimes would go to primary care clinics near their home to measure their weight. Barriers to purchasing scales include the cost associated with them, especially among pensioners and people from a low socio-economic background, and those who are vision impaired and need a costly talking scale.

The differences observed in the different parts of the world related to the self-care behavior of getting a flu shot are probably related to public awareness, policy and resources. And, in some countries poor (health) literacy might play a role. In terms of public awareness, it may be that not all HF patients are aware of the risks of influenza complications or the relationship between the flu and deterioration of HF, which might explain low adherence to this self-care behavior. On the other hand, in several countries an annual flu shot is free and provided locally by a primary healthcare provider or the public health service. In several countries in our study patients are routinely reminded to get a flu shot by their primary provider or at the HF clinic $[8,38]$. However, this is not the case in all countries and also not for all age groups. In some countries, only older people over age 65 will be included in these campaigns. In other countries, some (uninsured) patients still need to pay a small amount.

Similar to the local factors explaining differences in flu shots, adherence to a low salt diet may be related to difference in national $\mathrm{HF}$ guidelines, local food policies, available resources, and individual responses to suggested dietary changes. Although HF guidelines are inconsistent in the strength of their recommendation regarding the need for a strict sodium restriction of $2000 \mathrm{mg}$ (or less) for all HF patients [6,7], sodium restriction remains important in the management of heart failure [39].

Looking at the different countries involved, current salt intake in many countries is between 9 and $12 \mathrm{~g} /$ day. A moderate reduction in salt intake to the recommended level of 5-6 g/day would be consistent with the maximum intake recommended by the World Health Organization for all adults [40]. In our study it was most difficult for patients from the Eastern/Asian countries to follow a salt restriction self-care recommendation. This might be due to differences in guidelines for chronic HF (e.g., the Japanese guidelines recommend an average daily salt intake $\leq 7 \mathrm{~g}$ among patients with mild to moderate HF [41] or to the difficulty of preparing or purchasing salt restricted food (e.g., Kosher food is often high in sodium [42]) or prepared food in markets or local restaurants might be very high in sodium content.

In some countries governmental or non-governmental organizations have addressed the sodium issue and national recommendations and policies exist. Some countries have populationsbased campaigns aimed at reducing dietary sodium $[43,44]$. For example, in Thailand, the national campaign "Reduce Sodium Intake-to-Stop Chronic Disease" was implemented a few years ago with television and broadcasting media, Internet, posters, and booklets [45]. There is still a lack of clarity in the optimal sodium restriction, and healthy citizens, HF patients and health care providers struggle to know what is best. For example, different recommendations exist. For example in Sweden the recommended salt intake is $7 \mathrm{~g}$ of salt per day for men ( $2.8 \mathrm{~g}$ sodium) and $6 \mathrm{~g}$ salt per day for women [46] while in the Netherlands the recommended salt intake is $6 \mathrm{~g}$ a day for both men and women [47]. Even within countries there are several cultural habits that might call for separate approaches. For example, preliminary results from an ongoing study of 3850 adults living in the north, center and south of Italy, showed that the average intake of salt among Italians is 11 grams in males and $8 \mathrm{~g}$ in females daily [48]. That study also showed that salt intake is higher in the south than in the north of Italy.

Cultural differences might also exist regarding setting priorities between the various self-care behaviors. Knowledge about these priorities might help health care providers understand the motives of patients to implement certain self-care behaviors easily (e.g., diet) while others might not be implemented (e.g., symptom monitoring) [49].

Although this study is the first study comparing HF self-care internationally on a large scale in a typical older, chronic heart failure population, we realize that there are some limitations that suggest caution in interpreting our results. First, this was a secondary analysis of existing data from studies applying different inclusion and exclusion criteria, study designs and the data collected were for different aims and from different recruitment sites. Second, we pooled data that were collected with 2 different instruments. We therefore chose to use only the items that covered the same topics and not to include other self-care behaviors that were described differently in the two instruments. Thus, we realize that we did not paint the total picture of self-care behavior. We also did not have insight on patients' previous knowledge or experience with HF. In other words, in some countries patients might have obtained better information about HF self-care (e.g., in primary care, during hospitalization, in outpatient HF clinics). In some situations patients may have been so new to the diagnosis that they had not had an opportunity to practice self-care as yet.

\subsection{Conclusion}

Most self-care behaviors are poor and can be improved in HF patients. Several differences exist across and within cultures, continents and countries. A general improvement of the quality and the content of the education provided is needed to improve HF self-care of patients. Further changes in some health care system and national policies are needed in order to strengthen the possibilities for patients with HF to increase their self-care behavior.

\subsection{Practice implications}

Patients with heart failure need to cope with a lifelong regimen that involves more than simply medication taking. The lifestyle changes require support to help patients learn how to deal with the consequences of this chronic illness. Importantly, the support needed appears to differ by country. Specific self-care behaviors need a country- and culture-specific approach.

\section{Acknowledgement}

We would like to acknowledge the help of L. VerheijdenKlompstra for the support in combining all the data files.

\section{References}

[1] Lee CS, Moser DK, Lennie TA, Riegel B. Event-free survival in adults with heart failure who engage in self-care management. Heart Lung 2011;40:12-20. 
[2] Riegel B, Jaarsma T, Strömberg A. A middle-range theory of self-care of chronic illness. Adv Nurs Sci 2012;35:194-204.

[3] Lainscak M, Blue L, Clark AL, Dahlström U, Dickstein K, Ekman I, et al. Self-care management of heart failure: practical recommendations from the Patient Care Committee of the Heart Failure Association of the European Society of Cardiology. Eur J Heart Fail 2011;13:115-26.

[4] Riegel B, Moser DK, Anker SD, Appel LJ, Dunbar SB, Grady KL, et al. State of the science: promoting self-care in persons with heart failure: a scientific statement from the American Heart Association. Circulation 2009;120:1141-63.

[5] Moser DK, Dickson V, Jaarsma T, Lee C, Stromberg A, Riegel B. Role of self-care in the patient with Heart Failure. Curr Cardiol Rep 2012;4:265-75.

[6] Heart Failure Society of America, Lindenfeld J, Albert NM, Boehmer JP, Collins SP, Ezekowitz JA, et al. HFSA 2010 comprehensive heart failure practice guideline. J Card Fail 2010;16:e1-94.

[7] McMurray JJ, Adamopoulos S, Anker SD, Auricchio A, Böhm M, Dickstein K, et al. ESC Guidelines for the diagnosis and treatment of acute and chronic heart failure 2012: The Task Force for the Diagnosis and Treatment of Acute and Chronic Heart Failure 2012 of the European Society of Cardiology. Developed in collaboration with the Heart Failure Association (HFA) of the ESC. Eur J Heart Fail 2012;14:803-69.

[8] Krum H, Jelinek MV, Stewart S, Sindone A, Atherton JJ. 2011 Update to National Heart Foundation of Australia and Cardiac Society of Australia and New Zealand Guidelines for the prevention, detection and management of chronic heart failure in Australia, 2006. Med J Aust 2011;194:405-9.

[9] Ditewig JB, Blok H, Havers J, van Veenendaal H. Effectiveness of self-management interventions on mortality, hospital readmissions, chronic heart failure hospitalization rate and quality of life in patients with chronic heart failure: a systematic review. Patient Educ Couns 2010;78:297-315.

[10] Jaarsma T, Stromberg A, De Geest S, Fridlund B, Heikkila J, Martensson J, et al Heart failure management programmes in Europe. Eur J Cardiovasc Nurs 2006;4:197-205.

[11] van der Wal MH, Jaarsma T, Moser DK, van Gilst WH, van Veldhuisen DJ. Qualitative examination of compliance in heart failure patients in The Netherlands. Heart Lung 2010;39:121-30.

[12] McKinley S, Dracup K, Moser DK, Ball C, Yamasaki K, Kim CJ, et al. International comparison of factors associated with delay in presentation for AMI treatment. Eur J Cardiovasc Nurs 2004;3:225-30.

[13] Davidson PM, Macdonald P, Moser DK, et al. Cultural diversity in heart failure management: findings from the DISCOVER study (Part 2). Contemp Nurse 2007;25:50-61.

[14] Riegel B, Driscoll A, Suwanno J, Moser DK, Lennie TA, Chung ML, et al. Heart failure self-care in developed and developing countries. J Card Fail 2009;15:508-16.

[15] Riegel B, Carlson B, Moser DK, Sebern M, Hicks FD, Roland V. Psychometric testing of the self-care of heart failure index. J Card Fail 2004;10:350-60.

[16] Riegel B, Lee CS, Dickson VV, Carlson B. An update on the self-care of heart failure index. J Cardiovasc Nurs 2009;24:485-97.

[17] Jaarsma T, Stromberg A, Martensson J, Dracup K. Development and testing of the European Heart Failure Self-Care Behaviour Scale. Eur J Heart Fail 2003;5:363-70.

[18] Jaarsma T, Arestedt KF, Martensson J, Dracup K, Stromberg A. The European Heart Failure Self-care Behaviour scale revised into a nine-item scale (EHFScB9): a reliable and valid international instrument. Eur J Heart Fail 2009;11: 99-105.

[19] Gonzalez B, Lupon L, Parajon T, Urrutia A, Herreros J, Valle V. Use of the European Heart Failure Self-care Behavioral Scale (EHFScBS) in a heart failure unit in Spain. Rev Esp Cardiol 2006;59:166-70.

[20] Pulignano G, Del Sindaco D, Minardi G, Tarantini L, Cioffi G, Bernardi L, et al. Translation and validation of the Italian version of the European Heart Failure Self-care Behaviour Scale. J Cardiovasc Med (Hagerstown) 2010;11:493-8.

[21] Kato N, Ito N, Kinugawa K, Kazuma K. Validity and reliability of the Japanese version of the European Heart Failure Self-Care Behavior Scale. Eur J Cardiovas Nurs 2008;7:284-9.

[22] Shuldham C, Theaker C, Jaarsma T, Cowie MR. Evaluation of the European Heart Failure Self-care Behaviour Scale in a United Kingdom population. J Adv Nurs 2007;60:87-95.

[23] Köberich S, Glattacker M, Jaarsma T, Lohrmann C, Dassen T. Validity and reliability of the German version of the 9-item European Heart Failure Selfcare Behaviour Scale. Eur J Cardiovasc Nurs 2012. http://dx.doi.org/10.1177/ 1474515112438639

[24] Kroeber AL, Kluckhohn C. Culture: a critical review of concepts and definitions. Harvard University, Peabody Museum of American Archeology and Ethnology, Papers 47; 1952.
[25] Ory MG. The resurgence of self-care research: addressing the role of context and culture. J Cross-Cult Gerontol 2008:23:313-7.

[26] van der Wal MH, Jaarsma T, Moser DK, Veeger NJ, van Gilst WH, van Veldhuisen DJ. Compliance in heart failure patients: the importance of knowledge and beliefs. Eur Heart J 2006;27:434-40.

[27] Filho JMC, Marcopito LF, Castelo A. Medication use patterns among elderly people in urban area in Northeastern Brazil. Rev Saúde Pública 2004;38. 55764557.

[28] Cline CM, Björck-Linné AK, Israelsson BY, Willenheimer RB, Erhardt LR. Noncompliance and knowledge of prescribed medication in elderly patients with heart failure. Eur J Heart Fail 1999;1:145-9.

[29] Riegel B, Lee CS, Ratcliffe SJ, De Geest S, Potashnik S, Patey M, et al. Predictors of objectively measured medication nonadherence in adults with heart failure. Circ Heart Fail 2012;5:430-6.

[30] Fialová D, Topinková E, Gambassi G, Finne-Soveri H, Jónsson PV, Carpenter I, et al. Potentially inappropriate medication use among elderly home care patients in Europe. J Am Med Assoc 2005;293:1348-58.

[31] Hung J-Y, Chiou C-J, Chang H-Y. Relationships between medical beliefs of superiority of Chinese or western medicine, medical behaviours and glycaemic control in diabetic outpatients in Taiwan. Health Soc Care Community 2012;20:80-6.

[32] Chun-Chuan S, Yi-Chang S, Chien-Chang L, Jaung-Geng L. Patterns of medical pluralism among adults: results from the 2001 National Health Interview Survey in Taiwan. BMC Health Serv Res 2010;10:191-9.

[33] Sociedade Brasileira de Medicina do Exercício e do Esporte [homepage na Internet]. São Paulo: The Society [atualizada em 2010 jun 18; acesso 2012 jun em 18]. Available: http://cc.bingj.com/cache.aspx? $\mathrm{q}=1 \% 2 \mathrm{f} 3+\mathrm{dos}+\mathrm{idosos}+\mathrm{aci}-$ ma+de+65+anos+nao+faz+atividade+fisica. $\& d=4775179597512780 \& \mathrm{mkt}=\mathrm{pt}-$ BR\&setlang=pt-BR\&w=766089f3,70496844.

[34] http://www.abs.gov.au/ausstats/abs@.nsf/mf/4835.0.55.001 and http:// www.health.gov.au/internet/publications/publishing.nsf/Content/phd-physical-rec-older-disc $\sim$ chapter-3.

[35] Istituto Superiore di Sanità. Progetto cuore [heart project]; 2009. Istituto Superiore di Sanità, Rome, http://www.cuore.iss.it/fattori/anziani-sed.asp [last access 29.05.12].

[36] Wang RS, Chiou CJ. The participation of physical activity and its associated factors in the elderly. Kaohsiung J Med Sci 1996;12:348-58.

[37] Conraads VM, Deaton C, Piotrowicz E, Santaularia N, Tierney S, Piepoli MF, et al. Adherence of heart failure patients to exercise: barriers and possible solutions: a position statement of the Study Group on Exercise Training in Heart Failure of the Heart Failure Association of the European Society of Cardiology. Eur J Heart Fail 2012;14:451-8.

[38] Ying-Chun L, Chi-Mei L. Threat-responsiveness and the decision to obtain free influenza vaccinations among the older adults in Taiwan. BMC Public Health 2009;9:275-80.

[39] Gupta D, Georgiopoulou VV, Kalogeropoulos AP, Dunbar SB, Reilly CM, Sands JM, et al. Dietary sodium intake in heart failure. Circulation 2012;126:479-85.

[40] He FJ, Burnier M, Macgregor GA. Nutrition in cardiovascular disease: salt in hypertension and heart failure. Eur Heart J 2011;32:3073-80.

[41] The Japanese Circulation Society: Guidelines for Treatment of Chronic Heart Failure (JCS 2010). http://www.j-circ.or.jp/guideline/pdf/JCS2010_matsuzaki_h.pdf. (in Japanese).

[42] Hajmeer MN, Marsden JL, Fung DY, Kemp GK. Water, sodium chloride and acidified sodium chlorite effects on Escherichia coli 0157:H7 and Staphylococcus aureus on beef briskets. Meat Sci 2004;68:277-83.

[43] Smith-Spangler CM, Juusola JL, Enns EA, Owens DK, Garber AM. Population strategies to decrease sodium intake and the burden of cardiovascular disease: a cost-effectiveness analysis. Ann Intern Med 2010;152:481-7. W170-483.

[44] Strazzullo P, Cairella G, Campanozzi A, Carcea M, Galeone D, Galletti F, et al. Population based strategy for dietary salt intake reduction: Italian initiatives in the European framework. Nutr Metab Cardiovasc Dis 2012;22:161-6.

[45] http://www.en.thaihealth.or.th and http://www.thaincd.com.

[46] http://www.slv.se.

[47] http://www.rivm.nl/Bibliotheek/Algemeen_Actueel/Nieuwsberichten/2012/ Nederlanders_eten_ongezond_veel_zout.

[48] Donfrancesco D. Consumo medio giornaliero di sodio e potassio nella popolazione italiana adulta [Daily intake of sodium and potassium in adult Italian population]; 2010. http://www.salute.gov.it/imgs/C_17_newsAree_1092_listaFile_itemName_8_file.pdf [last access 28.05.12].

[49] Swerissen H, Belfrage J, Weeks A, Jordan L, Walker C, Furler J, et al. 5.A randomised control trial of a self-management program for people with a chronic illness from Vietnamese, Chinese, Italian and Greek backgrounds. Patient Educ Couns 2006;64:360-8. 